parents showed signs of contentment upon the timely action. Henceforth, I strongly urge readers to instigate the creative artist in each one of us while dealing with child patients.

D. S. V. Naga Sailaja, Hyderabad, Telangana, India

https://doi.org/10.1038/s41415-020-1797-y

\section{Virucidal activity}

Sir, I was disappointed to read the statement in an otherwise excellent document from the FGDP and College of General Dentistry that pre-treatment antiviral mouthwash was not recommended because of 'a lack of evidence of virucidal activity for use of pre-operative mouthwash'. I wonder if a flurry of recent papers, possibly overlooked, might lead to a questioning of that statement. What is now known is that SARS-CoV-2 replicates in the oral cavity and that extremely high numbers (>10 million) of infectious viral particles per $\mathrm{ml}$ saliva can be found at an early stage in SARS-CoV-2 infection. ${ }^{1}$ The virus in saliva is not contamination from elsewhere, but reflects active replication probably in ACE2 positive epithelial cells in minor salivary glands. ${ }^{2}$ Similar high levels are found in the nose. $^{3}$

This is clearly an infection risk to any clinician working around the mouth or nose. Any virucidal agent applied to those sites may substantially reduce the risk of cross infection. ${ }^{4}$

Several commonly used antiseptic mouthwashes with anti-bacterial activity also have anti-viral activity against coronaviruses demonstrated in vitro. ${ }^{5}$ Two (povidone iodine and ethanol) have been shown to have substantial activity against SARS-CoV-2 and one (PVP-I) SARS-CoV in the presence of organic matter designed to replicate in vivo conditions. ${ }^{6}$ What is not known is how effective any anti-viral mouthwash actually is in vivo, nor how long the antiviral effect lasts. This has been estimated as greater than 20 minutes. ${ }^{4}$ Thus, does one recommend withholding a potentially effective agent (thus potentially exposing substantial numbers of dental HCWs to extra risk), or does one recommend that a simple, cheap, safe and potentially effective agent is used to help safeguard the profession while the extra information is sought?

PVP-I has been used in dentistry for over 60 years and its safety profile well established. ${ }^{4}$ Over 24 dental HCWs have now died with SARS-CoV-2. Anything which helps to keep the profession as safe as possible is surely to be supported.

\section{S. J. Challacombe, London, V. S. Sunkaraneni,}

J. Kirk-Bayley, Guildford, UK

\section{References}

1. To KK-W, Tsang O T-Y, Yip C C-Y et al. Consistent detection of 2019 novel coronavirus in saliva. Clin Infect Dis 2020; 361: 1319. doi:10.1093/cid/ciaa149

2. Wu C, Zheng M. Single-cell RNA expression profiling shows that ACE2, the putative receptor of Wuhan 2019$\mathrm{nCoV}$, has significant expression in the nasal, mouth, lung and colon tissues. Preprints 2020. www. preprints. org (accessed 9 April 2020).

3. Zou L, Ruan F, Huang M et al. SARS-CoV-2 viral load in upper respiratory specimens of infected patients. New Eng/ J Med 2020; 382: 1177-1179. doi:10.1056/ NEJMc2001737

4. Kirk-Bayley J, Challacombe S J, Sunkaraneni V S, Combes J. The use of povidone iodine nasal spray and mouthwash during the current COVID-19 pandemic may reduce cross infection and protect healthcare workers. 4 May 2020. Available at https://www.researchgate. net/publication/340320238_The_Use_of_Povidone_ lodine_Nasal_Spray_and_Mouthwash_During_ the_Current_COVID-19_Pandemic_May_Protect Healthcare_Workers_and_Reduce_Cross_Infection (accessed June 2020).

5. Kampf G, Todt D, Pfaender S, Steinmann E. Persistence of coronaviruses on inanimate surfaces and their inactivation with biocidal agents. J Hosp Infect 2020; 104: 246-251.

6. Eggers M, Koburger-Janssen T, Eickmann M, Zorn J. In vitro bactericidal and virucidal efficacy of povidoneiodine gargle/mouthwash against respiratory and oral tract pathogens. Infect Dis Ther 2018; 7: 249-259.

https://doi.org/10.1038/s41415-020-1798-x

\section{Oncology patient support}

Sir, each year there are approximately

12,200 new cases of head and neck cancer diagnosed in the UK. ${ }^{1}$ For patients undergoing radiotherapy (either alone or in conjunction with resective surgery), the detrimental effects on oral health are well established, including the risk of developing osteoradionecrosis (ORN) of the jaws.

Preventative advice is paramount to reduce the need for future 'high risk' procedures including exodontia, which could initiate ORN. Clinical guidelines on the oral management of oncology patients recommend that adults are prescribed 5,000 ppm fluoride toothpaste and to rinse at least once daily with an alcohol free fluoride mouthrinse (0.05\%). However in reality, this is not always the case. For oncology patients without a regular GDP, or those who may have intermittent treatment in a tertiary dental centre, accessing prescriptions for high fluoride products may be particularly challenging during COVID-19. Although fluoridated products could be prescribed by patients' general medical practitioners (GMPs), funding restraints have resulted in NHS Clinical Commissioners advising against the routine prescription of high fluoride toothpaste in primary medical settings. ${ }^{2}$

We conducted a pilot survey investigating the awareness of ORN amongst GMPs and GMP trainees in the Midlands in 2019, the results demonstrating that this was very limited, but that there was a willingness to engage in teaching and education. The potential role for GMPs to support with preventative measures and vulnerable patients struggling to access routine dental care was identified. While dentists can continue support for these patients, future education and collaboration with our medical colleagues in primary care must also be considered in order to improve patient access, and ensure holistic patient care is being provided across all clinical settings. S. Lakhani, K. Martin, Birmingham, UK

\section{References}

1. Cancer Research UK. Head and Neck Cancer Statistics. 2017. Available at: https://www.cancerresearchuk.org/ health-professional/cancer-statistics/statistics-by-cancertype/head-and-neck-cancers\#heading-Four (accessed May 2020).

2. NHS England in association with NHS Clinical Commissioners. Conditions for which over the counter items should not routinely be prescribed in primary care: Guidance for CCGs. 2018. Available at: https:// www.england.nhs.uk/wp-content/uploads/2018/03/ otc-guidance-for-ccgs.pdf (accessed May 2020).

https://doi.org/10.1038/s41415-020-1799-9

\section{Test, test, test!}

Sir, there are two reasons why the current guidelines pose an existential risk to dental practice:

- The additional costs involved plus the required fallow periods make general practice dentistry unsustainable

- The necessity to approach our patients while dressed like Darth Vader will raise perceived levels of fear and panic among them. Many will think that our practices are 'hot beds' of COVID-19 infection and they will simply stay away.

The policy as it stands (both in terms of national control and the dental protocols) will simply allow us to lurch falteringly to the inevitable second lockdown, due in the autumn or winter. The only way forward is to take charge of our own profession and use our own applied knowledge and skills. There 